\title{
Au/Ag NPS Decorated PANI For Electrochemical and Biomedical Applications
}

\section{Singh $\mathbf{P}^{1^{*}}$, Patel $\mathbf{R}^{2}$, Kumari $\mathbf{K}^{3}$ and Mehrotra $\mathbf{G K}^{4}$}

${ }^{1}$ Department of Chemistry, Atma Ram Sanatan Dharma College, University of Delhi, Delhi, India

${ }^{2}$ The Centre for Interdisciplinary Research in Basic Sciences (CIRBS), Jamia Millia Islamia, New Delhi, India

${ }^{3}$ Department of Zoology, Deen Dayal Upadhyaya College, Delhi University, Delhi, India

${ }^{4}$ Department of Chemistry, Motilal Nehru National Institute of Technology Allahabad, Allahabad, Uttar Pradesh, India

\begin{abstract}
Polyaniline (PANI) has number of electronic structure and it depends on the doping. PANI composites containing $\mathrm{Fe}_{3} \mathrm{O}_{4} \mathrm{NPs}$ are regularly studied as the PANI having electrical and magnetic features. Herein, PANI was prepared from aniline and $\mathrm{HCl}$ by means of solution mixing using ammonium persulphate as oxidizing agent and catalyst. Composites of polyaniline with calcium carbonate and Au/Ag NPs were prepared. Nanocomposites of PANI were characterized using FTIR, SEM, EDX, electrical conductivity measurement techniques. The incorporation of $\mathrm{CaCO}_{3}$ and $\mathrm{Au} / \mathrm{Ag} \mathrm{NPs}$ in polyaniline matrix was confirmed by SEM, FT-IR and EDX results. $\mathrm{CaCO}_{3}$ act as binder and provide strength to the composite which can be clearly understood by SEM microgram. Electrochemical study of composite has been done which showed that on decorating PANI with gold/silver NPs, the conducting properties increases. We successfully tested the antimicrobial activity of nanocomposite via paper disk diffusion method against Escherichia coli and Staphylococcus aureus.
\end{abstract}

Keywords: Conducting polymer; Nanocomposite; Conductivity; Antibacterial

\section{Introduction}

In the present scenario, Conducting Polymers (CP) like polyaniline, polypyrrole and others take much attention of academician and researchers. It is because of both fundamental interest and potential applications in the, electro-chromic devices, energy storage and conversion systems, sensors anticorrosive coatings, and electro-catalysts etc. [1-6]. Some of the conducting polymers are soluble in water and/ or in organic solvents, which facilitates their application on surfaces as a thin film is one of the interesting property [7-10]. Polyaniline (PANI) has number of electronic structure and it depends on the doping. Oxidized and base-treated PANI (called emeraldine base) showed reduced conductivity on comparison with protonated Emaraldine Salt (ES) and therefore PANI is used as anticorrosive agent $[5,6]$.

PANI is very popular and suitable conductive synthetic polymers due to its low price, easily available and easy synthesis, manageable electric conductivity, high electro-activity and environmental solidity. Doped nano-composites based on conducting polymers and on different inorganic materials plays more important role in the advance of thoughts about nano-structuring, as nanocomposites show novel and rapidly improved mechanical, electronic, magnetic, optical and catalytic properties [2,3,5,8,9,11-14].

PANI composites containing $\mathrm{Fe}_{3} \mathrm{O}_{4} \mathrm{NPs}$ are regularly studied as the PANI having electrical and magnetic features. Researchers reported the synthesis of PANI nanocomposites containing $\mathrm{Fe}_{3} \mathrm{O}_{4} \mathrm{NPs}$ using chemical methods. These nanocomposites have more potential applications in comparison of PANI including anticorrosion coatings, batteries, sensors, separation membranes, and antistatic coatings [13,15]. They have diverse application potentials in electronics because incorporation of metal clusters, which increases the cluster of free electrons and enhance the conductivity of the polymer based nano-composites $[9,16]$. Several methods for the synthesis of metal NPs have been reported by various research groups like template method, photochemical preparation, electrochemical methods or electro-deposition of metal nanoparticles, reduction of metal salts etc. [5,17-25].
Herein, the synthesis of PANI based nanocomposites was carried out via simple methodology in normal condition via using cheap chemicals and easily available apparatus. The proposed synthesis is based on simple mixing of component (PANI, $\mathrm{CaCO}_{3}$ and $\mathrm{Au} / \mathrm{Ag} \mathrm{NPs}$ ) under appropriate condition.

\section{Experimental}

\section{Reagents and materials}

Chemicals used in the synthesis of the composite polymers are ammonium peroxydisulfate (LR), aniline (LR), hydrochloric acid (LR), sodium carbonate (LR), calcium chloride (LR), silver nitrate (LR), tetracholoauric acid and ammonia solution (LR) etc. Chemicals used were purchased from Molychem (India), SRL (India), Sigma-Aldrich (USA) etc. All the reactions were carried out in oven-dried glassware.

\section{Synthesis of polyaniline (PANI)}

PANI was synthesized by solution mixing technique. In this methodology, aniline polymerization was carried out in conc. $\mathrm{HCl}$ which was used to provide acidic media in the presence of ammonium persulfate, which acts as oxidant/initiator (Scheme 1).

In typical procedure, a beaker ( $1 \mathrm{~L}$ capacity) was taken and a solution of aniline $(8.33 \mathrm{~mL})$ in distilled water $(500 \mathrm{~mL})$ and $\mathrm{HCl}(50 \mathrm{~mL})$ were prepared. The reaction mixture was cooled with stirring at a temperature of $0-5^{\circ} \mathrm{C}$ for about $15 \mathrm{~min}$. Then, a solution of ammonium persulfate

*Corresponding author: Singh P, Department of Chemistry, Atma Ram Sanatan Dharma College, University of Delhi, Delhi, India, Tel: +91-11-24113436; E-mail: arsdchemistry@yahoo.in

Received March 17, 2017; Accepted March 27, 2017; Published March 31, 2017

Citation: Singh P, Patel R, Kumari K, Mehrotra GK (2017) Au/Ag NPS Decorated PANI For Electrochemical and Biomedical Applications. J Bioequiv Availab 9: 377 384. doi: $10.4172 / \mathrm{jbb} .1000328$

Copyright: @ 2017 Singh P, et al. This is an open-access article distributed under the terms of the Creative Commons Attribution License, which permits unrestricted use, distribution, and reproduction in any medium, provided the original author and source are credited. 
Citation: Singh P, Patel R, Kumari K, Mehrotra GK (2017) Au/Ag NPS Decorated PANI For Electrochemical and Biomedical Applications. J Bioequiv Availab 9: 377-384. doi: 10.4172/jbb.1000328

(18.924 $\mathrm{g}$ in $330 \mathrm{~mL}$ distilled water) was added dropwise to the above cooled reaction mixture with continuous stirring and this addition was completed in $2 \mathrm{~h}$. Solid precipitate was appeared after stirring of $3 \mathrm{~h}$ and then the reaction mixture was kept for overnight. Polymer (PANI) will settle down due to its high molecular weight and the unreacted aniline and oligomer will remain suspended in the supernatant and were separated out through decantation. After decantation $300 \mathrm{~mL}$ of distilled water was added and kept for 12-16 h. Then, the supernatant was discarded and this was repeated twice to avoid the presence of aniline or oligomers. Further, the precipitate was collected through filtration, followed by washing with distilled water. It was dried in oven at $40^{\circ} \mathrm{C}$ to afford the sample P1 (Yield=7.0194 g).

\section{Synthesis of $\mathrm{CaCO}_{3}$ microparticles}

The synthesis of $\mathrm{CaCO}_{3}$ microparticle was carried out by rapid mixing followed by fast stirring of aqueous solution of $\mathrm{Na}_{2} \mathrm{CO}_{3}$ and $\mathrm{CaCl}_{2}$ (Scheme 2).

In the typical procedure, an aqueous solution of $0.33 \mathrm{M} \mathrm{CaCl}_{2}(100$ $\mathrm{mL}$ solution) was taken in a flask ( $250 \mathrm{~mL}$ capacity) and then solution of $0.33 \mathrm{M} \mathrm{Na}_{2} \mathrm{CO}_{3}$ (100 mL solution) was added to above solution with continuous stirring at $40^{\circ} \mathrm{C}$. After intense agitation with a magnetic stirrer for $10 \mathrm{~min}$ and a white colour precipitate was obtained by sedimentation of the solution. Solid precipitate was washed with plenty of distilled water. Sedimentation of $\mathrm{CaCO}_{3}$ microparticle was done by centrifugation for $10 \mathrm{~min}$ at 4,000 rpm. (Yield=8.240 g)

\section{Preparation of tetrazolium or tetrazole ring based ionic liquid (1-Butyl-5-carboxymethyl-4-(2-cyano-ethyl)-4H-tetrazolium bromide)}

In the typical procedure, in a round bottom flask (100 mL capacity), 1-H-tetrazole-5-acetic acid $(10 \mathrm{mmol})$ and acrylonitrile $(10 \mathrm{mmol})$ in acetonitrile $(25 \mathrm{~mL})$ were stirred at room temperature $\left(30^{\circ} \mathrm{C}\right)$. The completion of the reaction was checked by thin layer chromatography (TLC) in mixture of hexane and ethyl acetate (1:9). After completion of the reaction, the solvent was removed under reduced pressure to get the product i.e., cyanoethyl tetrazole acetic acid [1-7,26-32]. Then, the obtained compound was taken in acetonitrile $(30 \mathrm{~mL})$ and equimolar bromobutane was added to the above solution with stirring. The above reaction mixture was refluxed for about $3 \mathrm{~h}$. Then, solvent was evaporated under reduced pressure to afford 1-Butyl-5-carboxymethyl4-(2-cyano-ethyl)-4H-tetrazolium bromide as in Scheme 3 [26-32] $\mathrm{C}_{10} \mathrm{H}_{16} \mathrm{~N}_{5} \mathrm{O}_{2}$; Pale green liquid. Synthesized ionic liquid was well characterized though FTIR, NMR techniques and the purity was checked using high performance liquid chromatography (HPLC). Analytical data: IR $(\mathrm{U}=\mathrm{cm}-1 ; \mathrm{KBr}) 3338(\mathrm{O}-\mathrm{H}), 3146(\mathrm{~N}-\mathrm{H}), 2962(\mathrm{C}-$ $\mathrm{CH}), 2361(\mathrm{CN}), 1749(\mathrm{C}=\mathrm{O})$; O-H $(9.39,1 \mathrm{H}) ; 1 \mathrm{H}-\mathrm{NMR}(\delta)$ aliphatic

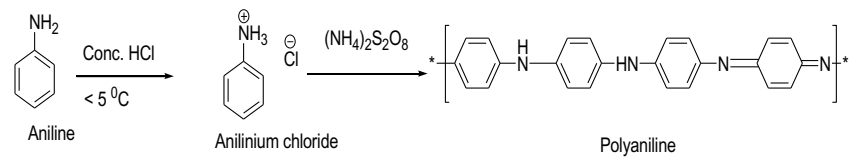

Scheme 1: Synthesis of PANI using aniline under acidic medium in the presence of ammonium persulphate.

$$
\mathrm{CaCl}_{2}+\mathrm{Na}_{2} \mathrm{CO}_{3} \underset{\text { Scheme 2: Synthesis of } \mathrm{CaCO}_{3} .}{\stackrel{\text { Stirring at } 30{ }^{\circ} \mathrm{C}}{\longrightarrow}} \mathrm{CaCO}_{3}+2 \mathrm{NaCl}
$$

hydrogen $(5.426,4 \mathrm{H}),(4.71,2 \mathrm{H}),(1.431,9 \mathrm{H}) ; 13 \mathrm{C}-\mathrm{NMR}(\delta)$ carbonyl carbons (168), nitrile (166), alkenic carbons (146), aliphatic carbon (66, $61,51,49,33,30)$.

\section{Synthesis of Au NPS in ionic liquid (1-butyl-5-carboxymethyl- 4-(2-cyano-ethyl)-4H-tetrazolium bromide)}

Herein, in a $10 \mathrm{~mL}$ round bottom flask, $5 \mathrm{ml}$ of the above synthesized ionic liquid and $10 \mathrm{mg}$ of tetrachloro auric acid $\left(\mathrm{HAuCl}_{4}\right)$ were taken and stirred for $10 \mathrm{~min}$ (yellow colour) and the mixture was treated with more of methanolic solution of sodium borohydride $(20 \mathrm{mg}$ in $10 \mathrm{ml}$ of methanol). A ruby red colored solution was obtained from yellow colour solution of $\mathrm{HAuCl}_{4}$ indicating the formation of gold in zero oxidation state. Stirring was continued for another $6 \mathrm{~h}$ for reduction of $\mathrm{Au}$ (III) to $\mathrm{Au}(0)$. Then the solution obtained was centrifuged for $10 \mathrm{~min}$ at $10,000 \mathrm{rpm}$ and the supernatant was discarded. Washed the centrifuged pellet with ethanol and the nanoparticles were analysed for characterization using powder X-ray Diffraction (XRD), transmission electron microscopy (TEM), quasi elastic light scattering (QELS) and UV-Visible techniques to determine shape, size and oxidation state of gold nanoparticles (Scheme 4).

\section{Synthesis of Ag NPs in the synthesized ionic liquid (1-Butyl-5- carboxymethyl-4-(2-cyano-ethyl)-4H-tetrazolium bromide)}

In a $10 \mathrm{~mL}$ round bottom flask, $5 \mathrm{~mL}$ of the above synthesized IL and $10 \mathrm{mg}$ of silver nitrate were taken and then addition of methanolic solution of sodium borohydride was done at $30^{\circ} \mathrm{C}$. Suddenly a yellowish brown color solution was obtained and signifying the silver NPs [2632]. Further, stirring was continued for $6 \mathrm{~h}$. Then suspended solution was poured into ethanol and centrifuged at $3000 \mathrm{rpm}$ for $10 \mathrm{~min}$ and decanted the supernatant and washed the pallet with ethanol and then the left material was analysed by powder X-ray Diffraction (XRD), Quasi Elastic Light Scattering (QELS), Transmission Electron Microscopy (TEM) and UV-Visible techniques to determine shape, size and oxidation state of Ag nanoparticles (Scheme 5).

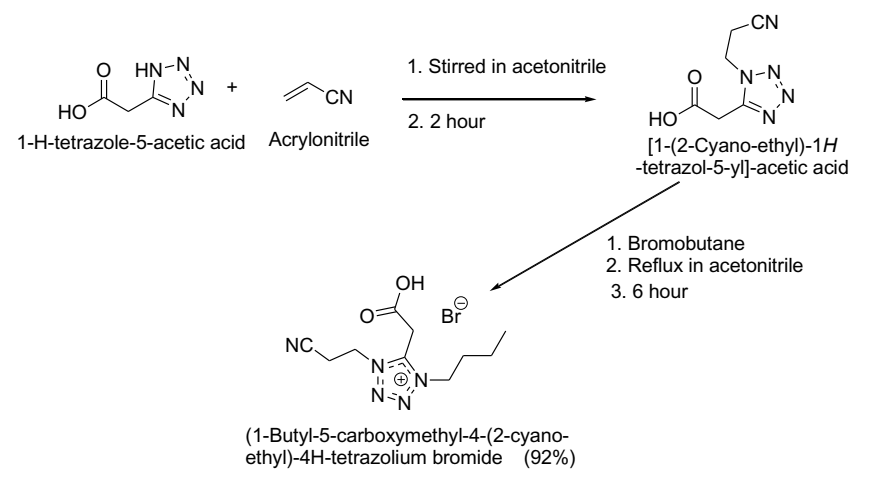

Scheme 3: Synthesis of ionic liquid (1-Butyl-5-carboxymethyl-4-(2-cyanoethyl)-4H-tetrazolium bromide).
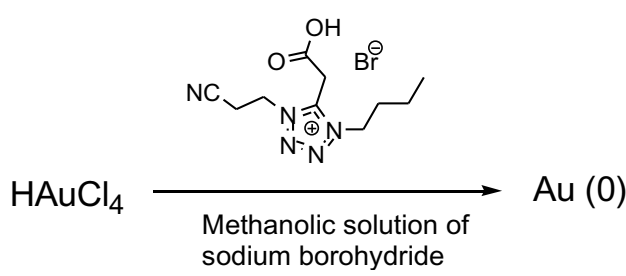

Scheme 4: Synthesis of gold NPs in ionic liquid. 
Citation: Singh P, Patel R, Kumari K, Mehrotra GK (2017) Au/Ag NPS Decorated PANI For Electrochemical and Biomedical Applications. J Bioequiv Availab 9: 377-384. doi: 10.4172/jbb.1000328

\section{Synthesis of PANI-CaCO${ }_{3}$-Au nanocomposites}

Composite nanopolymers of PANI were synthesized by mixing PANI, $\mathrm{CaCO}_{3}$ and $\mathrm{Au}$ NPs. In the typical procedure, different amounts of PANI (P2-P6 as mentioned in Table 1) were taken in a round bottom flask $(100 \mathrm{~mL})$ individually. Further, fixed amount of $\mathrm{CaCO}_{3}$ and $\mathrm{Au}$ NPs were added to the reaction mixture accordingly. The reaction mixture was stirred for appropriate time. On completion of reaction, the reaction mixture was centrifuged for $10 \mathrm{~min}$ at $8,000 \mathrm{rpm}$. Then, the supernatant was discarded and the pallet was used for the analysis and has been confirmed by several instrumental techniques (FTIR, SEM, EDX, impedance, cyclic voltametry etc.) (Scheme 6).

\section{Synthesis of $\mathrm{PANI}-\mathrm{CaCO}_{3}-\mathrm{Ag}$ nanocomposites}

Composite materials of PANI were synthesized by mixing PANI, $\mathrm{CaCO}_{3}$ and $\mathrm{Ag} \mathrm{NPs}$. In the typical procedure, different amounts of

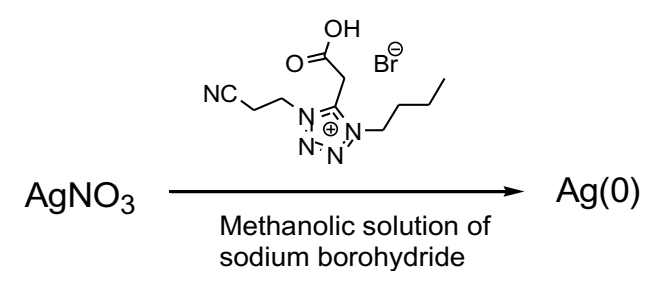

Scheme 5: Synthesis of silver NPs in ionic liquid.

\begin{tabular}{|c|c|c|c|c|}
\hline S. No. & Sample No. & PANI (mg) & $\left.\mathbf{C a C O}_{\mathbf{3}} \mathbf{( m g}\right)$ & $\begin{array}{c}\mathbf{2 0} \mathbf{~ m L} \text { dispersed } \\
\text { solution of metal NPs }\end{array}$ \\
\hline 1 & P1 & + & - & - \\
\hline 2 & P2 & 1000 & 100 & $\mathrm{Au}$ \\
\hline 3 & P3 & 800 & 100 & $\mathrm{Au}$ \\
\hline 4 & P4 & 600 & 100 & $\mathrm{Au}$ \\
\hline 5 & P5 & 400 & 100 & $\mathrm{Au}$ \\
\hline 6 & P6 & 200 & 100 & $\mathrm{Au}$ \\
\hline 7 & P7 & 1000 & 100 & $\mathrm{Ag}$ \\
\hline 8 & P8 & 800 & 100 & $\mathrm{Ag}$ \\
\hline 9 & P9 & 600 & 100 & $\mathrm{Ag}$ \\
\hline 10 & P10 & 400 & 100 & $\mathrm{Ag}$ \\
\hline 11 & P11 & 200 & 100 & $\mathrm{Ag}$ \\
\hline
\end{tabular}

Table 1: PANI and its composite with calcium carbonate and Au/Ag NPs.
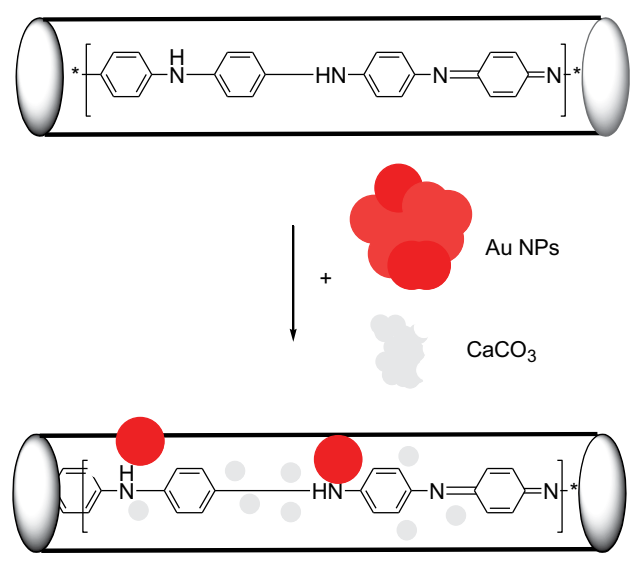

Scheme 6: Schematic representation for the synthesis of PANI$\mathrm{CaCO}_{3}$-Au nanocomposite.
PANI (P7-P11 as in Table 1) were taken in a round bottom flask (100 $\mathrm{mL}$ ) individually. Then, fixed amount of $\mathrm{CaCO}_{3}$ and $\mathrm{Ag}$ NPs were added to the reaction mixture accordingly. The reaction mixture was stirred for appropriate time. On completion of reaction, the reaction mixture was centrifuged for $10 \mathrm{~min}$ at $8,000 \mathrm{rpm}$. Then, the supernatant of the reaction mixture was discarded and the Centrifugated pallet was used for the analysis and has been confirmed by several instrumental techniques (FTIR, SEM, EDX, impedance, cyclic voltametry etc.) (Scheme 7).

\section{Instrumentation}

\section{Fourier transform infra-red (FTIR) spectroscopy}

Synthesized samples (P1-P11) were analysed via making their pallet using $\mathrm{KBr}$ as background and ratio is 1:99. Samples were crushed by hydraulic pressure to make pellets. Finely these pellets were analysed using FTIR spectrophotometer to determine different kind of bond stretching.

\section{Scanning electron microscopy (SEM)}

All the synthesized samples (P1-P11) were coated on carbon tape for the analysis. SEM micrographs of samples P1-P11 have been collected using scanning electron microscope. SEM model JSM 6490 LV may be used under low as well as high vaccum depending on the behaviour of the specimens. Low vaccum with low $\mathrm{kV}$ (energy) offers the user the lengthier duration for scanning the composites, before it is charged and the charging of composites was done with platinum source.

\section{Energy-dispersive X-ray (EDX) spectroscopy}

It is used to determine the composition of element present in the composite material. EDS 133, EV Dry Detector (INCAx-act) of OXFORD instruments, UK, were used for analysis, it has improved the application range in a way that any metal connected with the polymer may be identified and also can be quantified. This instrument is coupled with scanning electron microscope.

\section{Cyclic voltammetry}

$\mathrm{CH}$ instrument 604E USA was used to study the electrochemical activity of the composites using three probe systems in aqueous system. Cyclic voltammetry technique is used to determine composites on
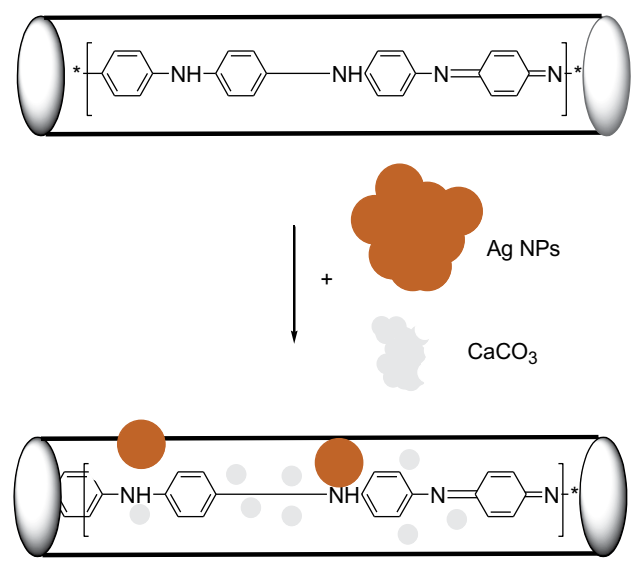

Scheme 7: Schematic representation for the synthesis of PANI$\mathrm{CaCO}_{3}$-Ag nanocomposite. 
Citation: Singh P, Patel R, Kumari K, Mehrotra GK (2017) Au/Ag NPS Decorated PANI For Electrochemical and Biomedical Applications. J Bioequiv Availab 9: 377-384. doi: 10.4172/jbb.1000328

varying the potential with respect to current. Further, it determines the oxidation and reduction of the material.

\section{AC \& DC conductivity}

AC conductivities of the samples via impedance spectroscopy have been determined using electrochemical analyser, $\mathrm{CH}$ instrument $604 \mathrm{E}$ USA at ARSD College, Delhi University. DC conductivity measurements were done with Kiethley 236 Current Source-meter at Delhi University.

\section{Antibacterial activity study of PANI-CACO $-\mathrm{Au} / \mathrm{Ag}$ NPs}

The antibacterial activity of the synthesized composites PANI$\mathrm{CACO}_{3}-\mathrm{Au} / \mathrm{Ag} \mathrm{NPs}$ were evaluated against Escherichia coli and Staphylococcus aureus microorganisms via paper disk diffusion method. This process is without a doubt a means of measuring the competence of an antibacterial agent against said bacteria. Herein, suspensions of the bacteria culture were inoculated and their concentrations attuned by comparing with the McFarland turbidity of $0.4-0.5\left(1.5 \times 10^{8} \mathrm{CFU}\right)$. We have taken Muller-Hinton Agar (MHA) powder to provide a culture medium for the growth of the bacterial. Approximately $19 \mathrm{~g}$ of agar was taken and dissolved in double distilled water $(500 \mathrm{~mL})$ and then we obtained a clear brown colour solution after boiling of the mixture. Further, MHA medium $(15 \mathrm{ml})$ was sterilized at a temperature of $12^{\circ} \mathrm{C}$ for approximately $60 \mathrm{~min}$ in the autoclave, then it was cooled to room temperature, and then the MHA was poured into sterilized petri-plates $(10 \times 90 \mathrm{~mm})$. Bacteria i.e., E. coli and S. aureus of our interest, was cleansed uniformly across a culture plate, while the petri-plates were cooled over $24 \mathrm{~h}$. Then, as per the requirement, filter-paper disks were placed on the surface of the medium and $40 \mu \mathrm{l}$ of each concentration of PANI-CACO $-\mathrm{Au} / \mathrm{Ag} \mathrm{NPs}$ samples were dropped over disks to investigate antibacterial activity.

If the composites are active against the mentioned microorganism of a known concentration, then colonies of microorganism will not grow. If the Concentration in the agar is found greater or equal to the effective concentration then this region is known as the zone of inhibition. This area or size of zone of inhibition tells the potency of the composites. A more potential composite gave more clear area just about the disk of filter paper. All the tests against the above mentioned microorganism were carried out under laminar flow hood. At last, all the Petri-plates having microorganisms and composites were incubated at $37^{\circ} \mathrm{C}$ for a time period of $24 \mathrm{~h}$. Then, study the inhibition zones created around each paper disk and usually come in $\mathrm{mm}$. Literature showed indicated if the zone of inhibition is $>13 \mathrm{~mm}$ means strong activity, if $6-12 \mathrm{~mm}$ then moderate activity, and for $5 \mathrm{~nm}$ means weak activity and for $<5$ nm, no activity.

\section{Results and Discussion}

\section{FTIR spectra}

The composite polymers synthesized using PANI-CaCO$-\mathrm{Au} / \mathrm{Ag}$ NPs have been characterized using FTIR spectroscopic technique. It was observed that on decorating PANI with metal NPs, shift in the wavenumber for various stretching as mentioned in Table 2 and the spectra are given in Figure 1.

\section{SEM and EDX-micrograph}

In order to evaluate the dispersion of $\mathrm{CaCO}_{3}$ and metal $(\mathrm{Au}, \mathrm{Ag})$ NPs in the polyaniline matrix, the scanning electron micrograph was recorded of PANI-CaCO - Gold/Silver NPs nanoparticle composites. Figure 2 (P1-P11) showed the SEM micrograph of PANI and its composites i.e., PANI-CaCO- -Gold/ Silver NPs composites. SEM micrograph confirms the good dispersion of $\mathrm{CaCO}_{3}$ particles and $\mathrm{Au} /$ $\mathrm{Ag}$ NPs in the polyaniline matrix. An examination of PANI under SEM microgram, it is clear that PANI is amorphous with sponge like morphology. Incorporation of $\mathrm{CaCO}_{3}$ particles in PANI increases the strength of composite materials and decreases the amorphousness character.

Incorporation of $\mathrm{Au} / \mathrm{Ag}$ NPs in the PANI matrix was established by Energy dispersive X-ray (EDX spectroscopy). The spectra obtained are given with corresponding SEM micrograph which clearly indicates the presence of gold/silver NPs in the PANI matrix. The EDX data were also given in Table 3 .

\section{Cyclic voltammetry analysis}

Cyclic Voltammetry analysis of PANI and its composites (P1P11) were studied. Cyclic voltammetry is a dynamic electrochemical approach, wherein change in current is determined at well-defined applied potential which depends on the scan rate, and therefore, the current-potential curves have been plotted. The determined oxidation potential of an electroactive material relates directly with the ionization potential Ip and reduction potential with the electron affinity Ea. Ideally, one peak couple signify oxidation and reduction potential should seem in the cyclic Voltagram measurement for the Valence Band (VB) and the Conduction Band (CB), respectively. The composites were then exposed to Cyclic Voltammetry (CV) technique in $0.5 \mathrm{M} \mathrm{HCl}$ solution. It is known that polyaniline experiences two separate oxidation and reduction processes. It is evidently observed to be occurring in the films prepared here. The distinct oxidation-reduction responses show that the composite is electroactive. The first response is because of oxidation-reduction of leucoemeraldine to emeraldine and vice-versa. More the range of current more will be the charge-discharge and will be more stable.

\begin{tabular}{|c|c|}
\hline Sample & Stretching bands $\left(U=\mathrm{cm}^{-1}\right)$ \\
\hline P1 & $3852.9,3725.9,3664.6,3435.9,3207.4,2944.9,2909.9,2829.0,2256.8,1560.9,1480.5,1296.3,1242.3,1135.0,879.1,798.5,699.4,594.2,504.8$ \\
\hline P2 & $3438.4,3208.7,2944.8,2897.1,2830.9,1560.6,1477.2,1296.8,1241.4,1130.0,878.4,797.8,700.9,592.5,503.8$ \\
\hline P3 & $3435.9,2829.0,1560.9,1480.5,1296.3,1242.3,879.1,798.5$ \\
\hline P4 & $3385.8,2950.9,1796.1,1583.0,1491.5,1135.2,867.3,828.3$ \\
\hline P5 & $3312.1,2912.9,1765.3,1575.1,1491.5,1143.0,875.5,828.3$ \\
\hline P6 & $33098.5,29105.5,1745.1,1570.8,1475.9,11425.9,858.1,810.9$ \\
\hline P7 & $3398.2,2513.3,1796.6,1583.6,1434.0,1146.7,875.4,828.1,711.4,512.3$ \\
\hline P8 & $3264.2,2885.1,2825.7,2357.8,2045.1,1641.9,1593.3,1294.3,1241.3,1125.2,980.5,877.8,794.2,682.9,643.9,627.4,580.5,563.7,500.9$ \\
\hline P9 & $3435.7,2978.5,2892.3,2329.8,2116.6,1571.5,1483.3,1294.9,1240.9,1145.0,878.8,796.1,700.5,503.4$ \\
\hline P10 & $3206.6,2905.4,2827.5,2356.2,1558.8,1479.0,1295.8,1241.4,1140.0,878.8,797.3,701.1,592.4,502.4$ \\
\hline P11 & $3189.0,2898.5,2805.8,2342.7,1547.0,1432.9,1279.9,1237.6,1110.6,854.5,785.7,695.0,585.1,500.1$ \\
\hline
\end{tabular}

Table 2: FTIR data of PANI and its composites (P1-P11). 
Citation: Singh P, Patel R, Kumari K, Mehrotra GK (2017) Au/Ag NPS Decorated PANI For Electrochemical and Biomedical Applications. J Bioequiv Availab 9: $377-384$. doi: $10.4172 / j b b .1000328$

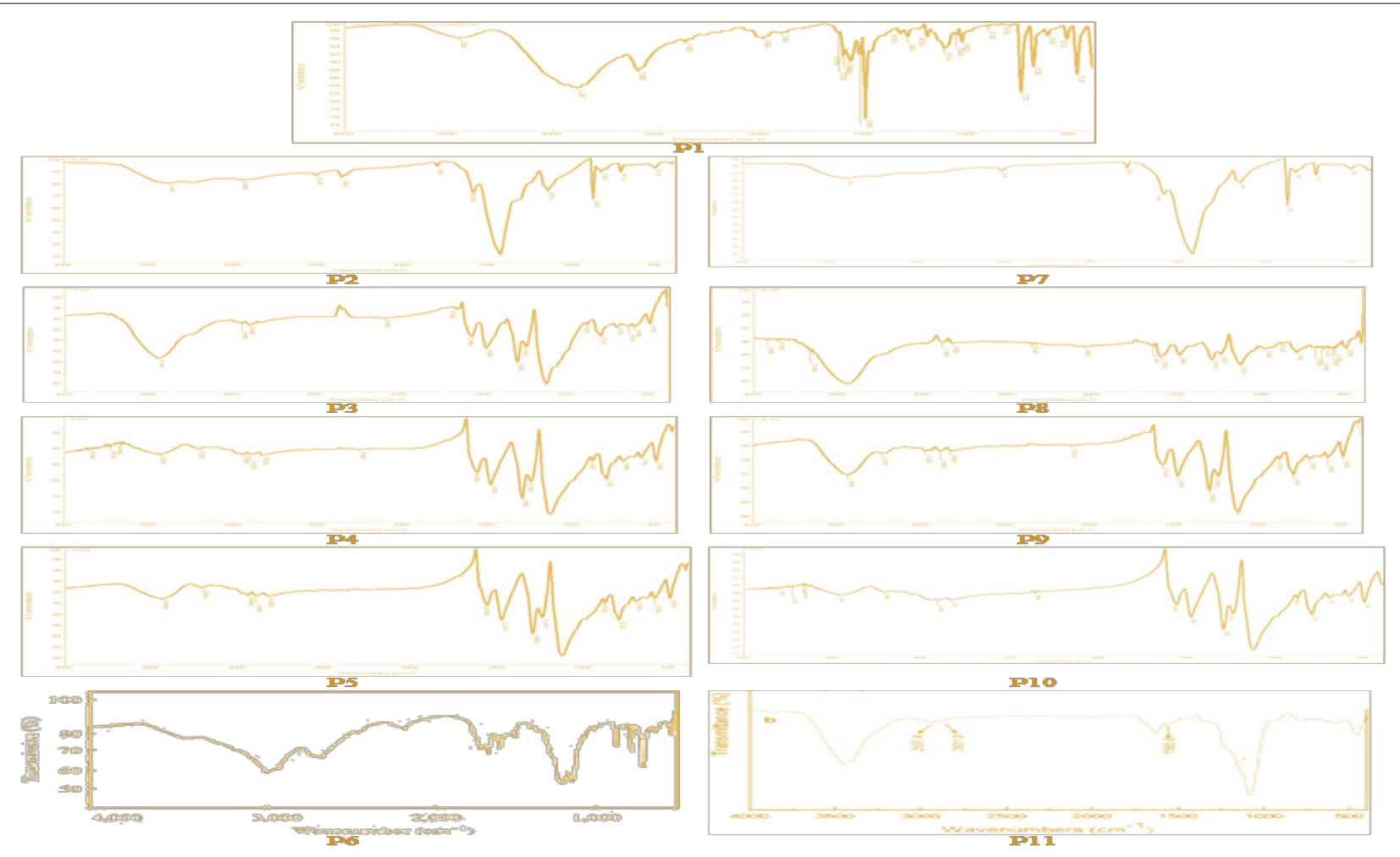

Figure 1: FTIR spectra of PANI and its composites (P1-P11).

\section{$\mathrm{AC}$ and DC conductivity measurement}

Impedance spectroscopy technique was known to determine the AC conductivity of the material using col and col plot. It was found that the P7 gave the best conductivity. Impedance $(\mathrm{Z})$ and angle were used to determine $\mathrm{ZCos} \Theta$ and $\mathrm{ZSin} \Theta$ and by drawing a plot between $\mathrm{ZCos} \Theta$ and $\mathrm{ZSin} \Theta$, we get the intercept on $\mathrm{x}$-axis, known as impedance and also known as the resistance. Therefore, we can calculate conductivity of the compound from:

$$
\text { Resistance }=(\text { Resistivity } \times \text { Length }) /(\text { Area })
$$

and

\section{Conductivity $=1 /$ Resistivity}

In another case, DC conductivity was determined by plotting the current v/s voltage as explained in ohm's law. DC conductivity measurements were done using Kiethley 236 Current Source-meter. DC and AC conductivity of PANI (P1) and its composite material (P2-P11) were compared (Table 4). It was found that the composite materials had significant AC conductivity than DC conductivity. On the basis of data obtained, it was concluded that these compounds are only frequency dependent and are current independent. Conductivity for P7 was found out to maximum. It means more the doping with metal NPs, more will be the conductivity.

\section{Antibacterial properties of prepared synthesized PANI- $\mathrm{CACO}_{3}-\mathrm{Au} / \mathrm{Ag} \mathrm{NPs}$}

In our study, PANI-CACO $-\mathrm{Au} / \mathrm{Ag}$ NPs were tested for antibacterial activity using E. coli and S. aureus. On treating the microorganism with the nanocomposites in the form of solution, their inhibition zones were detected. Diameter of the inhibition zones against E. coli and $S$. aureus respectively are mentioned in Table 5 . It was observed that PANI-CACO $-\mathrm{Au} / \mathrm{Ag}$ NPs having different concentration of metal NPs showed good antibacterial activity when compared with PANI.

Metal NPs (Ag \& Au) exhibit good antibacterial activity which may lead to biomedical applications. The antibacterial activity of $\mathrm{Ag}$ and $\mathrm{Au}$ NPs are dependent on metal NPs how effectively they bind and it came to know that Ag and Au NPs binds effectively to electron donating groups available on biological macromolecules like sulphur, oxygen or nitrogen. At low concentrations of metal NPs, interaction of NPs with the cell wall of bacteria decreases and as we increase the concentration of metal NPs, the probability of aggregation increases. It result the operative surface to volume ratio of NPs and therefore, resulting interaction between NPs and the cell wall decrease.

\section{Conclusion}

PANI was prepared from aniline and $\mathrm{HCl}$ by means of solution mixing using ammonium persulphate as oxidizing agent and catalyst. Composites of polyaniline with calcium carbonate and $\mathrm{Au} / \mathrm{Ag}$ NPs were prepared. Nanocomposites of PANI were characterized using FTIR, SEM, EDX, electrical conductivity measurement techniques. The incorporation of $\mathrm{CaCO}_{3}$ and $\mathrm{Au} / \mathrm{Ag}$ NPs in polyaniline matrix was confirmed by SEM, FT-IR and EDX results. $\mathrm{CaCO}_{3}$ act as binder and provide strength to the composite which can be understood by SEM microgram. Electrochemical analysis of composite material of PANI showed that on decorating with gold/silver NPs, the conducting properties increases. It was also found that the composite materials had significant AC conductivity than DC conductivity. So we conclude that these compounds are frequency dependent and are current 
Citation: Singh P, Patel R, Kumari K, Mehrotra GK (2017) Au/Ag NPS Decorated PANI For Electrochemical and Biomedical Applications. J Bioequiv Availab 9: 377-384. doi: 10.4172/jbb. 1000328

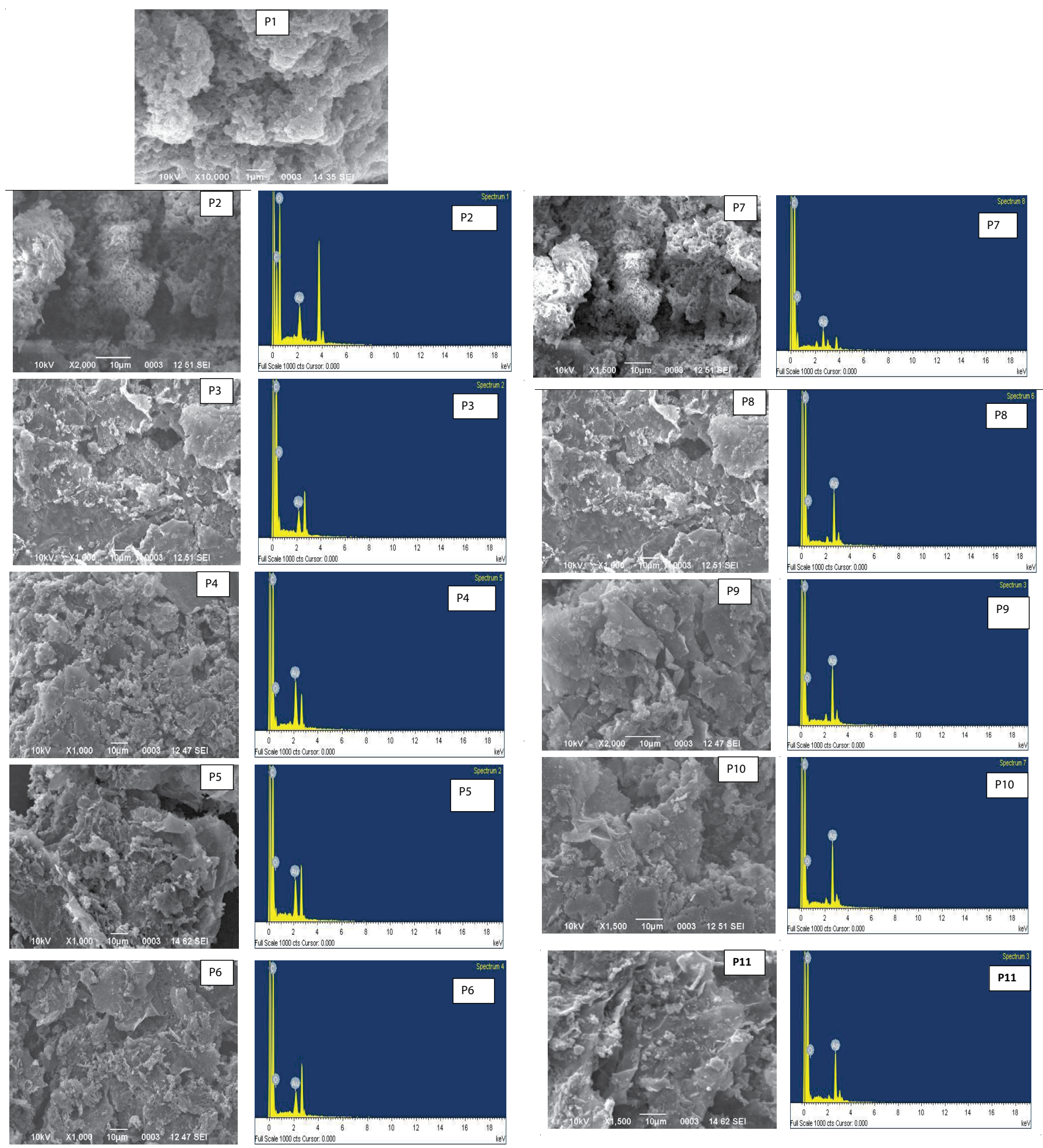

Figure 2: SEM and EDX picture of samples (P1-P11) as in Table 1.

independent. Conductivity for sample P6 and P11 were found out maximum. It means more the doping with metal NPs, more will be the conductivity. The results show clearly the good efficiency of synthesized polymers in nanoparticle coating because the particle size was obtained in the acceptable range of 10-17 $\mathrm{nm}$. The applied method is simple and of low cost and does not use many chemicals unlike other methods. PANI-CACO 3 - Au/Ag NPs were tested for antibacterial activity using $E$. coli and S. aureus and showed good antibacterial activity. 
Citation: Singh P, Patel R, Kumari K, Mehrotra GK (2017) Au/Ag NPS Decorated PANI For Electrochemical and Biomedical Applications. J Bioequiv Availab 9: 377-384. doi: 10.4172/jbb.1000328

\begin{tabular}{|c|c|c|c|c|}
\hline S. No. & Sample No. & Element & Weight $\%$ & Atomic\% \\
\hline 1 & $\mathrm{P} 1$ & - & - & - \\
\hline 2 & $\mathrm{P} 2$ & $\mathrm{Au}$ & 8.60 & 0.68 \\
\hline 3 & $\mathrm{P} 3$ & $\mathrm{Au}$ & 4.44 & 0.29 \\
\hline 4 & $\mathrm{P} 4$ & $\mathrm{Au}$ & 8.92 & 0.61 \\
\hline 5 & $\mathrm{P} 5$ & $\mathrm{Au}$ & 11.60 & 0.82 \\
\hline 6 & $\mathrm{P} 6$ & $\mathrm{Au}$ & 14.95 & 1.10 \\
\hline 7 & $\mathrm{P} 7$ & $\mathrm{Ag}$ & 3.87 & 0.48 \\
\hline 8 & $\mathrm{P} 8$ & $\mathrm{Ag}$ & 5.05 & 0.61 \\
\hline 9 & $\mathrm{P} 9$ & $\mathrm{Ag}$ & 5.50 & 0.68 \\
\hline 10 & $\mathrm{P} 10$ & $\mathrm{Ag}$ & 5.77 & 0.71 \\
\hline 11 & $\mathrm{P} 11$ & $\mathrm{Ag}$ & 6.8 & 0.84 \\
\hline
\end{tabular}

Table 3: Percentage of Au/Ag NPs in the synthesized composite polymers.

\begin{tabular}{|c|c|c|c|}
\hline S. No. & Samples & $\begin{array}{l}\text { AC conductivity } \\
\left({ }^{*} 10^{-3} \mathrm{mho} \mathrm{m}^{-1}\right)\end{array}$ & $\begin{array}{l}\text { DC conductivity } \\
\left({ }^{*} 10^{-10} \mathrm{mho} \mathrm{m}^{-1}\right)\end{array}$ \\
\hline 1 & P1 & 0.9564 & 1.4565 \\
\hline 2 & P2 & 1.2341 & 0.0505 \\
\hline 3 & P3 & 2.4546 & 0.0544 \\
\hline 4 & P4 & 2.9842 & 0.0765 \\
\hline 5 & P5 & 5.1324 & 0.1856 \\
\hline 6 & P6 & 3.4235 & 0.1512 \\
\hline 7 & P7 & 1.4563 & 0.0956 \\
\hline 8 & P8 & 1.6345 & 0.1235 \\
\hline 9 & P9 & 2.5645 & 0.1456 \\
\hline 10 & P10 & 4.6532 & 0.2326 \\
\hline 11 & P11 & 8.3265 & 0.4521 \\
\hline
\end{tabular}

Table 4: Comparison AC and DC conductivity of the samples (P1-P11).

\begin{tabular}{|c|c|c|c|}
\hline S. No. & Samples & Samples Average of formed inhibition zones (mm) \\
\cline { 2 - 4 } & & 5 & Escherichia coli \\
\hline 1 & P1 & 8 & 6 \\
\hline 2 & P2 & 8 & 8 \\
\hline 3 & P3 & 9 & 8 \\
\hline 4 & P4 & 11 & 8 \\
\hline 5 & P5 & 12 & 10 \\
\hline 6 & P6 & 6 & 13 \\
\hline 7 & P7 & 6 & 7 \\
\hline 8 & P8 & 6 & 7 \\
\hline 9 & P9 & 6 & 8 \\
\hline 10 & P10 & 7 & 8 \\
\hline 11 & P11 & 9 \\
\hline
\end{tabular}

Table 5: Inhibition zones obtained from nanocomposites against two pathogenic bacteria.

\section{References}

1. Chandra S, Lang H, Bahadur D (2013) Polyaniline-iron oxide nanohybrid film as multi-functional label-free electrochemical and biomagnetic sensor for catechol.Anal Chim Acta 795: 8-14

2. Attia NF, Geckeler KE (2013) Polyaniline-polypyrrole composites with enhanced hydrogen storage capacities.Macromol Rapid Commun 34: 931-937.

3. Attia NF, Geckeler KE (2013) Polyaniline as a material for hydrogen storage applications.Macromol Rapid Commun 34: 1043-1055.

4. Gu H, Tadakamalla S, Huang Y, Colorado HA, Luo Z, et al. (2012) Polyaniline stabilized magnetite nanoparticle reinforced epoxy nanocomposites.ACS Appl Mater Interfaces 4: 5613-5624.

5. Dmitrieva E, Dunsch L (2011) How linear is "linear" polyaniline?J Phys Chem B 115: 6401-6411.

6. Canales M, Curcó D, Alemán C (2010) Modeling of amorphous polyaniline emeraldine base. J Phys Chem B 114: 9771-9777.
7. Du M, Yang T, Li X, Jiao K (2012) Fabrication of DNA/graphene/polyaniline nanocomplex for label-free voltammetric detection of DNA hybridization. Talanta 88: 439-444.

8. Boomi P, Prabu HG, Mathiyarasu J (2013) Synthesis and characterization of polyaniline/Ag-Pt nanocomposite for improved antibacterial activity.Colloids Surf B Biointerfaces 103: 9-14.

9. Chen F, Liu P (2011) Conducting polyaniline nanoparticles and their dispersion for waterborne corrosion protection coatings.ACS Appl Mater Interfaces 3: 2694-2702.

10. Arya SK, Dey A, Bhansali S (2011) Polyaniline protected gold nanoparticles based mediator and label free electrochemical cortisol biosensor. Biosens Bioelectron 28: 166-173.

11. Liao Y, Yu DG, Wang X, Chain W, Li XG, et al. (2013) Carbon nanotubetemplated polyaniline nanofibers: synthesis, flash welding and ultrafiltration membranes.Nanoscale 5: 3856-3862.

12. Jeon JW, O'Neal J, Shao L, Lutkenhaus JL (2013) Charge storage in polymer acid-doped polyaniline-based layer-by-layer electrodes. ACS Appl Mater Interfaces 5: 10127-10136.

13. Bian L, Bao L, Wang J, Lei J (2013) In situ preparation of monodispersed Ag/ polyaniline/Fe3O4 nanoparticles via heterogeneous nucleation. Nanoscale Res Lett 8: 309.

14. Dandan R, Xu J, Lingling X, Yan Z (2011) Preparation of polyaniline modified electrode in novel ionic liquid and its application in ion chromatography. $J$ Chromatogr Sci 49: 612-616.

15. Mukherjee P, Nandi AK (2011) Concomitant synthesis of polyaniline and highly branched gold nanoparticles in the presence of DNA. J Colloid Interface Sci 356: 145-150.

16. Cui C, Du Y, Li T, Zheng X, Wang X, et al. (2012) Synthesis of electromagnetic functionalized $\mathrm{Fe}_{3} \mathrm{O}_{4}$ microspheres/polyaniline composites by two-step oxidative polymerization. J Phys Chem B 116: 9523-9531.

17. Arslan F, Beskan U (2014) An amperometric biosensor for glucose detection from glucose oxidase immobilized in polyaniline-polyvinylsulfonate-potassium ferricyanide film.Artif Cells Nanomed Biotechnol 42: 284-288.

18. Park HW, Kim T, Huh J, Kang M, Lee JE, et al. (2012) Anisotropic growth contro of polyaniline nanostructures and their morphology-dependent electrochemical characteristics. ACS Nano 6: 7624-7633.

19. Cui Y, Chen H, Tang D, Yang H, Chen G (2012) Au(III)-promoted polyaniline gold nanospheres with electrocatalytic recycling of self-produced reactants for signal amplification. Chem Commun (Camb) 48: 10307-10309.

20. Chaudhuri D, Sarma DD (2006) Blue emitting polyaniline. Chem Commun (Camb) pp: 2681-2683

21. Li C, Yan J, Hu X, Liu T, Sun C, et al. (2013) Conductive polyaniline helixes self-assembled in the absence of chiral dopant.Chem Commun (Camb) 49 1100-1102.

22. McGrath N, Patil AJ, Watson SM, Horrocks BR, Faul CF, et al. (2013) Conductive, monodisperse polyaniline nanofibers of controlled length using well-defined cylindrical block copolymer micelles as templates. Chemistry 19: 13030-13039.

23. Ameen S, Akhtar MS, Kimi YS, Yang OB, Shin HS (2011) Electrical and structural characterization of plasma polymerized polyaniline/TiO2 heterostructure diode: a comparative study of single and bilayer $\mathrm{TiO}_{2}$ thin film electrode. $\mathrm{J}$ Nanosci Nanotechnol 11: 3306-3313.

24. Afzal AB, Akhtar MJ, Ahmad M (2010) Morphological studies of DBSA-doped polyaniline/PVC blends. J Electron Microsc (Tokyo) 59: 339-344.

25. Prathap AMU, Chaurasia AK, Sawant SN, Apte SK (2012) Polyaniline-based highly sensitive microbial biosensor for selective detection of lindane. Ana Chem 84: 6672-6678.

26. Singh P, Kumar K, Tomar V, Rana DK, Chandra R (2010) Effect of oxygen partial pressure on the structural \& optical properties of sputter deposited $\mathrm{ZnO}$ thin films. Curr Chem Res pp: 5-7.

27. Singh P, Kumari K, Katyal A, Kalra R, Chandra R (2009) Synthesis and characterization of silver and gold nanoparticles in ionic liquid. Spectrochim Acta A Mol Biomol Spectrosc 73: 218-220. 
Citation: Singh P, Patel R, Kumari K, Mehrotra GK (2017) Au/Ag NPS Decorated PANI For Electrochemical and Biomedical Applications. J Bioequiv Availab 9: 377-384. doi: 10.4172/jbb.1000328

28. Singh P, Kumari K, Katyal A, Kalra R, Chandra R (2009) Copper Nanoparticles in Ionic Liquid: An Easy and Efficient Catalyst for Selective Carba-Michael Addition Reaction. Cat Lett 127: 119-125.

29. Singh P, Kumari K, Katyal A, Kalra R, Chandra R (2009) Cu Nanoparticles in Ionic Liquid: An Easy and Efficient Catalyst for Addition-Elimination Reaction Between Active Methylene Compounds and Imines in an Ionic Liquid. Cat Lett 130: $648-654$
30. Singh P, Kumar S, Katyal A, Kalra R, Chandra R (2008) A novel route for the synthesis of indium nanoparticles in ionic liquid. Mat Lett 62: 4164-4166.

31. Singh P, Katyal, A Kalra, R, Chandra R (2008) Copper nanoparticles in ionic liquid: An easy and efficient catalyst for the coupling of thiazolidine-2,4-dione, aromatic aldehyde and ammonium acetate. Cat Comm 9: 1618-1623.

32. Singh P, Katyal A, Kalra R, Chandra R (2008) Copper nanoparticles in an ionic liquid: an efficient catalyst for the synthesis of bis-(4-hydroxy-2-oxothiazolyl) methanes. Tet Lett 49: 727-730. 